\title{
Regulation of Alcohol Extinction and Cue-Induced Reinstatement by Specific Projections among Medial Prefrontal Cortex, Nucleus Accumbens, and Basolateral Amygdala
}

\author{
[Colby R. Keistler, ${ }^{1,2}$-Emma Hammarlund, ${ }^{1}$ Jacqueline M. Barker, ${ }^{4}$ Colin W. Bond, ${ }^{1,2}$ Ralph J. DiLeone, ${ }^{1,2}$ \\ CChristopher Pittenger, ${ }^{1,2,3}$ and Jane R. Taylor ${ }^{1,2,3}$ \\ ${ }^{1}$ Department of Psychiatry, Division of Molecular Psychiatry, ${ }^{2}$ Interdepartmental Neuroscience Program, and ${ }^{3}$ Department of Psychology, Yale University, \\ New Haven, Connecticut 06510, and ${ }^{4}$ Department of Neurosciences, Medical University of South Carolina, Charleston, South Carolina 29425
}

The ability to inhibit drinking is a significant challenge for recovering alcoholics, especially in the presence of alcohol-associated cues. Previous studies have demonstrated that the regulation of cue-guided alcohol seeking is mediated by the basolateral amygdala (BLA), nucleus accumbens (NAc), and medial prefrontal cortex (mPFC). However, given the high interconnectivity between these structures, it is unclear how mPFC projections to each subcortical structure, as well as projections between BLA and NAc, mediate alcohol-seeking behaviors. Here, we evaluate how cortico-striatal, cortico-amygdalar, and amygdalo-striatal projections control extinction and relapse in a rat model of alcohol seeking. Specifically, we used a combinatorial viral technique to express diphtheria toxin receptors in specific neuron populations based on their projection targets. We then used this strategy to create directionally selective ablations of three distinct pathways after acquisition of ethanol self-administration but before extinction and reinstatement. We demonstrate that ablation of mPFC neurons projecting to NAc, but not BLA, blocks cue-induced reinstatement of alcohol seeking and neither pathway is necessary for extinction of responding. Further, we show that ablating BLA neurons that project to NAc disrupts extinction of alcohol approach behaviors and attenuates reinstatement. Together, these data provide evidence that the $\mathrm{mPFC} \rightarrow \mathrm{NAc}$ pathway is necessary for cueinduced reinstatement of alcohol seeking, expand our understanding of how the BLA $\rightarrow$ NAc pathway regulates alcohol behavior, and introduce a new methodology for the manipulation of target-specific neural projections.

Key words: alcohol; basolateral amygdala; extinction; medial prefrontal cortex; nucleus accumbens; reinstatement

\section{Significance Statement}

The vast majority of recovering alcoholics will relapse at least once and understanding how the brain regulates relapse will be key to developing more effective behavior and pharmacological therapies for alcoholism. Given the high interconnectivity of cortical, striatal, and limbic structures that regulate alcohol intake, it has been difficult to disentangle how separate projections between them may control different aspects of these complex behaviors. Here, we demonstrate a new approach for noninvasively ablating each of these pathways and testing their necessity for both extinction and relapse. We show that inputs to the nucleus accumbens from medial prefrontal cortex and amygdala regulate alcohol-seeking behaviors differentially, adding to our understanding of the neural control of alcoholism.

\section{Introduction}

Alcohol is the most widely used drug (Substance Abuse and Mental Health Services Administration, 2014) and alcohol use disor-

Received Oct. 31, 2016; revised March 1, 2017; accepted March 15, 2017

Author contributions: C.R.K., J.M.B., R.J.D., C.P., and J.R.T. designed research; C.R.K., E.H., and C.W.B. performed research; C.R.K., E.H., and C.W.B. analyzed data; C.R.K. and J.R.T. wrote the paper.

This work was supported by the National Institutes of Health (Grant MH091861 to C.P., Grant DK098994 to R.J.D., Grant AA012870 to J.R.T., and Grant AA024673 to C.R.K.); the Allison Family Foundation (C.P.); and the Connecticut Department of Mental Health and Addiction Services. We thank Meiyu Xu for generating the DTR virus, the UPenn Vector Core for generating the AAV6-Cre virus, and Ben Land for helpful discussions and insights. ders place a significant burden on public health and economies worldwide. Like other drug addictions, alcoholism is considered a chronic relapsing disease that is characterized by an inability to control drinking (Koob and Volkow, 2010). Relapse to alcohol

The authors declare no competing financial interests.

Correspondence should be addressed to Jane R. Taylor Ph.D., Department of Psychiatry, Division of Molecular Psychiatry, Yale University, Connecticut Mental Health Center, Ribicoff Labs, 34 Park St., New Haven, CT 06508. E-mail: jane.taylor@yale.edu.

DOI:10.1523/JNEUROSCI.3383-16.2017

Copyright $\odot 2017$ the authors $\quad 0270-6474 / 17 / 374462-10 \$ 15.00 / 0$ 
use can be driven by a variety of factors, including the presence of environmental or sensory cues that were previously paired with alcohol intake. These relapse events depend on associative learning processes whereby cues paired with a positive reinforcer such as alcohol gain the ability to trigger cravings and motivate behaviors to obtain that reinforcer (Weiss, 2005; Heinz et al., 2009; Bossert et al., 2013). In both recovering alcoholics and rodent models of intake, cue-triggered relapse can occur even after instrumental processes have been extinguished (Ciccocioppo et al., 2001; Field and Duka, 2002; Lê and Shaham, 2002; Sinha and Li, 2007). Developing more effective behavioral and pharmacological treatments for alcoholism will require a better understanding of the neural circuitry that underlies both extinction and cuetriggered relapse to alcohol intake.

Previous studies have shown that cue-induced alcohol seeking depends on the activity of limbic-striatal structures, especially basolateral amygdala (BLA) and nucleus accumbens (NAc) (Chaudhri et al., 2010; Sinclair et al., 2012; Millan et al., 2015; Sciascia et al., 2015), and that alcohol seeking is correlated with increased glutamatergic transmission in these structures (Gass et al., 2011). It is also known that alcohol-paired cues induce activity in mPFC (Dayas et al., 2007; Koob and Volkow, 2010) and alcohol seeking can be perpetuated by alterations in medial prefrontal cortex (mPFC) (Weiss, 2005; Heinz et al., 2009; Abernathy et al., 2010). Although it is thought that the loss of behavioral regulation in addiction results from dysfunction in mesocorticolimbic circuitry (Jentsch and Taylor, 1999; Ciccocioppo et al., 2001; Field and Duka, 2002; Sinha and Li, 2007), how specific afferents in these pathways control cue-triggered alcohol seeking, especially in the early stages of alcohol intake, is still unclear. Given the high interconnectivity of neural circuits, traditional methods such as lesions and inactivation have been unable to identify the role of specific projections among $\mathrm{mPFC}$, NAc, and BLA.

Here, we used a novel approach to ablate directionally specific subpopulations of mPFC neurons defined by their projection target. To accomplish this, we combined a retrogradely transported Cre virus with a floxed diphtheria toxin receptor (DTR)encoding virus. By expressing floxed DTR in the mPFC and infusing retrograde Cre virus into either NAc or BLA, DTRs are expressed selectively in $\mathrm{mPFC}$ neurons projecting to either of these subcortical structures. Because rodents do not express DTR endogenously (Coca et al., 1921; Middlebrook and Dorland, 1977; Naglich and Eidels, 1990), only the targeted pathway is subject to ablation via systemic injection of diphtheria toxin (DT). We used this system to test separately the necessity of the $\mathrm{mPFC} \rightarrow \mathrm{NAc}, \mathrm{mPFC} \rightarrow \mathrm{BLA}$, and $\mathrm{BLA} \rightarrow \mathrm{NAc}$ pathways in the extinction and reinstatement of alcohol seeking. Our data reveal three key findings: $(1)$ the $\mathrm{mPFC} \rightarrow \mathrm{NAc}$ pathway is necessary for cue-induced reinstatement, but not extinction, of alcohol seeking; (2) the $\mathrm{mPFC} \rightarrow \mathrm{BLA}$ pathway is not necessary for extinction or reinstatement of alcohol seeking; and (3) the BLA $\rightarrow$ NAc pathway is necessary for the extinction of approach behavior and regulates the reinstatement of alcohol seeking. Together, these data provide insight into the role of specific circuits in the regulation of alcohol-related behaviors.

\section{Materials and Methods}

Animals

Experimentally naive male Sprague Dawley rats (Charles River Laboratories, RRID: RGD_737891) were housed in pairs on a 12:12 h light/dark cycle in a temperature- and humidity-controlled environment. Rats weighed 225-275 g upon arrival and were acclimated to the housing facility for 1 week before surgery. Rats were allowed to recover from surgery before being food restricted to $90-92 \%$ of their free-feeding weights. All surgical and behavioral procedures were approved by the Yale University Institutional Animal Care and Use Committee and were consistent with the National Institutes of Health's Guidelines on the Care and Use of Laboratory Animals.

\section{Surgical procedures}

Surgeries were performed at least 1 week before the start of self-administration training. Rats were anesthetized with $75 \mathrm{mg} / \mathrm{kg}$ ketamine $+10 \mathrm{mg} / \mathrm{kg}$ xylazine (i.m.) and mounted on a stereotaxic frame. For both $\mathrm{mPFC} \rightarrow \mathrm{NAc}$ and $\mathrm{mPFC} \rightarrow$ BLA ablations, AAV6.2.CMV.PI.Cre.rBG [UPenn Vector Core; lot CS0164-TC; titer $=2.34 \mathrm{e} 13$ genomic copies $(\mathrm{gc}) / \mathrm{ml})]$ was infused into either NAc (AP + 1.5, ML 0.85, DV -7.6) or BLA (AP - 2.8, ML 5.0, DV $-8.7 / 8.4$; half-volume at each site). AAV6 was infused at a volume of $0.5 \mu \mathrm{l}$ over a $10 \mathrm{~min}$ period and allowed to diffuse for $5 \mathrm{~min}$ after injection. AAVrh10 CAG.EGFP.FLEX.DTRFLAG.WPRE.pA (described in Xu et al., 2016; A46, titer $=\sim 10^{13} \mathrm{gc} / \mathrm{ml}$ ) was injected bilaterally into $\mathrm{mPFC}$ $(\mathrm{AP}+3.0, \mathrm{ML} 0.4, \mathrm{DV}-4.0)$ at a volume of $0.25 \mu \mathrm{l}$. AAVrh10-DTR was injected at $0.05 \mu \mathrm{l} / \mathrm{min}$ and allowed to diffuse for $10 \mathrm{~min}$. For the BLA $\rightarrow \mathrm{NAc}$ experiments, AAV6-Cre was injected into NAc (same volume and rates given above) and AAVrh10-DIO-DTR was injected into BLA (0.2 $\mu \mathrm{l} / \mathrm{side}$, DV: -8.7$)$. See Figure $1 A$ for a summary. All viral injections were performed with $0.5 \mu$ l Hamilton syringes with 25 gauge needles.

\section{Behavioral experiments}

Apparatus. All alcohol-seeking experiments were conducted in standard Med Associates operant chambers $(30 \times 20 \times 25 \mathrm{~cm})$ enclosed in soundand light-attenuating cabinets. Each chamber contained a metal rod floor, house light, clicking noise generator, and two retractable levers on either side of a recessed magazine chamber. A motorized dipper arm delivered $0.1 \mathrm{ml}$ of the ethanol/saccharin solution into the magazine port and head entries were detected by a photocell mounted inside the reinforcer receptacle.

Preexposure to ethanol. After surgery, animals were allowed to recover for $5 \mathrm{~d}$ and were then food restricted to $90-92 \%$ of their freefeeding body weight. Before beginning behavioral training, animals underwent $2 \mathrm{~d}$ of preexposure to the alcohol/saccharin solution to prevent neophobia. Each day, animals were left in their home cages but moved to a new room where they no longer had access to water and were allowed to eat freely for $15 \mathrm{~min}$. Bottles containing $10 \%$ ethanol $+0.1 \%$ saccharin were then placed on the wire cage tops and rats were allowed to sample the solution for $60-90 \mathrm{~min}$. The volume of solution consumed was recorded and animals were returned to the colony.

Operant alcohol self-administration. After $2 \mathrm{~d}$ of preexposure, animals were introduced to the behavioral training chambers. Training began with one magazine session to orient the animals with the location of reward delivery. During this session, 61 dippers were delivered on a fixed interval $25 \mathrm{~s}$ schedule and the dipper arm remained raised for $10 \mathrm{~s}$. Starting the next day, rats received daily sessions in which both levers were extended and they learned to press one ("active lever") for delivery of the alcohol reinforcer on a fixed ratio 1 (FR1) schedule. The dipper arm remained raised for $10 \mathrm{~s}$ and, during this time, the house light flashed at $1 \mathrm{~Hz}$ and 3 clicks were presented. The sessions terminated when an animal had administered 30 dipper deliveries of alcohol or after $60 \mathrm{~min}$ had passed. After reaching behavioral criteria of $\geq 20$ dipper deliveries in a single session, each animal received $19 \mathrm{~d}$ of FR1 training. All subjects consistently administered 30 dippers per day, resulting in total daily delivery of $3 \mathrm{ml}$ of $10 \%$ ethanol. Animals were then randomly assigned to receive intraperitoneal injection of either DT $(30 \mu \mathrm{g} / \mathrm{kg})$ or saline $(1 \mathrm{ml} / \mathrm{kg})$ immediately after the $19^{\text {th }}$ session and received one additional day of alcohol selfadministration. The time point for injection was chosen based on previous studies showing robust and long-lasting effects on both behavior and cellular markers of apoptosis at $48 \mathrm{~h}$ after DT injection (Gropp et al., 2005; Han et al., 2009). By injecting $48 \mathrm{~h}$ before the first extinction session, we therefore tested the effects of circuit ablation on both extinction and reinstatement. 
Extinction training. Immediately after day 20 of self-administration, animals underwent daily 15 min extinction sessions for 5-6 d or until responding had reached $<25 \%$ of baseline (calculated as average lever pressing during the last $3 \mathrm{~d}$ of self-administration). During extinction, levers were extended and the house light was illuminated, but lever presses were no longer consequential and resulted in neither alcohol nor audiovisual cue delivery. The ethanol + saccharin solution was left in the chamber throughout extinction but was inaccessible to the rat.

Cue-induced reinstatement test. The next day, animals were put back in the chambers and underwent a 15 min cue-induced reinstatement test. Immediately after the session initiated, they were exposed to one "free" noncontingent presentation of the alcohol-paired audiovisual cue. Subsequently, every response on the active lever resulted in presentation of the cue but not alcohol delivery.

\section{Immunohistochemistry}

Animals were deeply anesthetized with euthasol and perfused transcardially with chilled saline followed by $10 \%$ formalin. Brains were postfixed for $24 \mathrm{~h}$ then transferred to $30 \% \mathrm{w} / \mathrm{v}$ sucrose for $2-7 \mathrm{~d}$ before slicing. 35 Micrometer sections were washed $3 \times 5 \mathrm{~min}$ in $1 \times \mathrm{PBS}$, blocked in $3 \%$ normal donkey serum $/ 0.3 \%$ Triton-X/PBS for $60 \mathrm{~min}$, and then incubated overnight in blocking solution containing primary monocolonal antibodies directed toward FLAG (1:1000; Cell Signaling Technology 2368S; RRID:AB_2217020), Cre (1:500; Millipore MAB3120; RRID: AB_2085748), or c-Fos (1:500; Santa Cruz Biotechnology sc-52; RRID: AB_2629503). Slices were next washed $3 \times 5 \mathrm{~min}$ in $1 \times$ PBS and incubated for $2 \mathrm{~h}$ with species-appropriate Alexa Fluor 555-conjugated secondary antibodies (Abcam, 1:500). Slices were washed $3 \times 3 \mathrm{~min}$ in $1 \times$ PBS, mounted on slides, and coverslipped with Vectashield hard set mounting medium (Vector Laboratories). Apoptosis was evaluated with an antibody directed toward cleaved caspase-3 (Asp175; 1:5000; Cell Signaling Technology 9661S; RRID:AB_2341188) using a similar protocol as above except that slices were blocked for $120 \mathrm{~min}$ and both primary and secondary antibodies were diluted in buffer (1\% BSA/0.3\% Triton $\mathrm{X}-100)$. Slides were investigated using an Olympus fluorescent-equipped upright mounted microscope (with $5 \times, 10 \times$, and $20 \times$ objectives) and a Fluoview FV10i confocal microscope (with $10 \times$ and $20 \times$ objectives). Quantification was performed using the particle analysis function in ImageJ to count the number of stained nuclei in a $1.8 \mathrm{~mm}^{2}$ area within mPFC. Percentage FLAG + expression was calculated as the number of FLAG + cells divided by the total number of fluorescent cells (GFP + and FLAG +).

\section{Statistics}

Data are expressed as mean \pm SEM. All data were analyzed with the IMB SPSS Statistics package, version 23, using either $t$ tests or repeatedmeasures ANOVAs (rm-ANOVAs). The criterion for statistical significance was a probability level of $p<0.05$. For behavioral analyses, the between-subjects factor was treatment (DT or saline) and the withinsubject factor was training day.

\section{Results}

\section{Combinatorial viral approach renders specific mPFC} projections subject to ablation by DT

We combined a floxed DTR construct with a retrogradely transported AAV6-Cre virus to express DTRs in directionally specific neuronal projections. We first targeted the $\mathrm{mPFC} \rightarrow \mathrm{NAc}$ pathway (Fig. 1A), allowed 2 weeks for vial expression, and then systemically injected animals with saline, $15 \mu \mathrm{g} / \mathrm{kg} \mathrm{DT}$, or $30 \mu \mathrm{g} / \mathrm{kg}$ DT. Three weeks later, animals were perfused and slices from mPFC were stained with a FLAG-directed antibody. We found two populations of cells: GFP-expressing, Cre-negative neurons and DTR-FLAG-expressing, Cre-positive neurons (shown as green and red, respectively, in Fig. 1B). DT injection resulted in a dose-dependent reduction in total FLAG + cells (one-way ANOVA: $F_{(2,11)}=38.100, p<0.001$; post hoc Tukey tests $p \leq$ 0.015 for all comparisons) and percentage of FLAG + cells (Fig. $1 B, C ; F_{(2,11)}=24.638, p<0.001$; post hoc Tukey tests $p \leq 0.018$ for all comparisons), with no difference between treatment groups in GFP expression $\left(F_{(2,11)}=2.491, p=0.138\right)$. Cre labeling in the NAc shows that AAV-6 expression is restricted to the NAc, with expression in both dorsal shell and mediodorsal core regions (Fig. $1 D$ ).

Previous work in DTR-expressing mouse models has shown that apoptosis markers are upregulated $48 \mathrm{~h}$ after DT injection (Han et al., 2009) and that DT-induced neuronal ablation has measurable behavioral effects as early as $24 \mathrm{~h}$ after injection (Gropp et al., 2005). To ensure a similar apoptosis time course in our model, we killed a separate group of rats $48 \mathrm{~h}$ after DT or saline injection and stained for cleaved caspase-3. We then quantified cleaved caspase- 3 expression and found a significant upregulation in toxin-treated animals (Fig. $1 F$ ). Qualitative analysis revealed similar cleaved caspase-3 expression levels in off-target regions (motor cortex and cingulate), suggesting that differences were localized to areas of DTR-FLAG expression.

\section{Ablation of mPFC neurons projecting to the NAc blocks cue-induced reinstatement of alcohol seeking}

Before injection of saline or toxin, all animals were trained to self-administer alcohol on an FR1 schedule. As expected, rm ANOVA revealed that both groups of animals increased their lever pressing across the $20 \mathrm{~d}$ of training $(n=6$ /group; main effect of day, $\left.F_{(19,209)}=3.014, p<0.001\right)$ with no significant difference between those rats that would receive saline and those that would receive toxin (effect of future treatment $F_{(1,11)}=$ $1.419, p=0.295$, future treatment $\times$ day $F_{(19,209)}=0.421, p=$ $0.985)$. Immediately after the completion of self-administration, animals began extinction training, during which presses on the active lever were recorded but did not result in delivery of alcohol or alcohol-paired cues. rmANOVA of lever pressing during extinction training revealed that both saline- and DT-treated animals decreased lever pressing over the course of extinction (Fig. $2 B$; main effect of day: $F_{(4,40)}=21.334, p<0.001$ ), with no effect of treatment $\left(F_{(1,10)}=0.748, p=0.407\right)$ and no treatment by day interaction $\left(F_{(4,40)}=0.372, p=0.827\right)$. Similarly, both groups extinguished magazine entries with no effect of treatment or interaction between day and treatment (Fig. 2E; effect of day: $F_{(4,40)}=4.451, p=0.005$; treatment: $F_{(1,10)}=0.302, p=0.594$; day $\times$ treatment: $\left.F_{(1,10)}=0.249, p=0.629\right)$. These results suggest that ablation of $\mathrm{mPFC}$ neurons projecting to NAc does not affect acquisition of extinction of alcohol seeking.

After extinction training, animals underwent a cue-induced reinstatement test. For each group (saline- and toxin-treated), lever pressing during the last extinction session was compared with lever pressing during the reinstatement test to evaluate the ability of alcohol-paired cues to reinstate alcohol seeking. rmANOVA revealed a main effect of session (Fig. $2 C ; F_{(1,10)}=$ $14.699, p=0.003)$ and a trend toward a main effect of treatment $\left(F_{(1,10)}=4.687, p=0.056\right)$, with a significant treatment by session interaction $\left(F_{(1,10)}=5.203, p=0.046\right)$. Subsequent pairedsample $t$ tests revealed that saline-treated animals showed a significant increase in responding during the cue-induced reinstatement test versus the last extinction session $\left(t_{(5)}=-3.860\right.$, $p=0.012)$, but toxin-treated animals did not $\left(t_{(5)}=-1.272, p=\right.$ $0.259)$. Similar rmANOVA analyses revealed no effect of treatment on reinstatement of magazine entries (Fig. 2F; effect of session: $F_{(1,9)}=5.358, p=0.046$; effect of treatment n.s.: $F_{(1,9)}=$ $0.478, p=0.507$; session $\times$ treatment interaction n.s.: $F_{(1,9)}=$ $0.016, p=0.902)$. These results suggest that the $\mathrm{mPFC} \rightarrow \mathrm{NAc}$ pathway is necessary for cue-induced reinstatement of lever pressing for alcohol. 

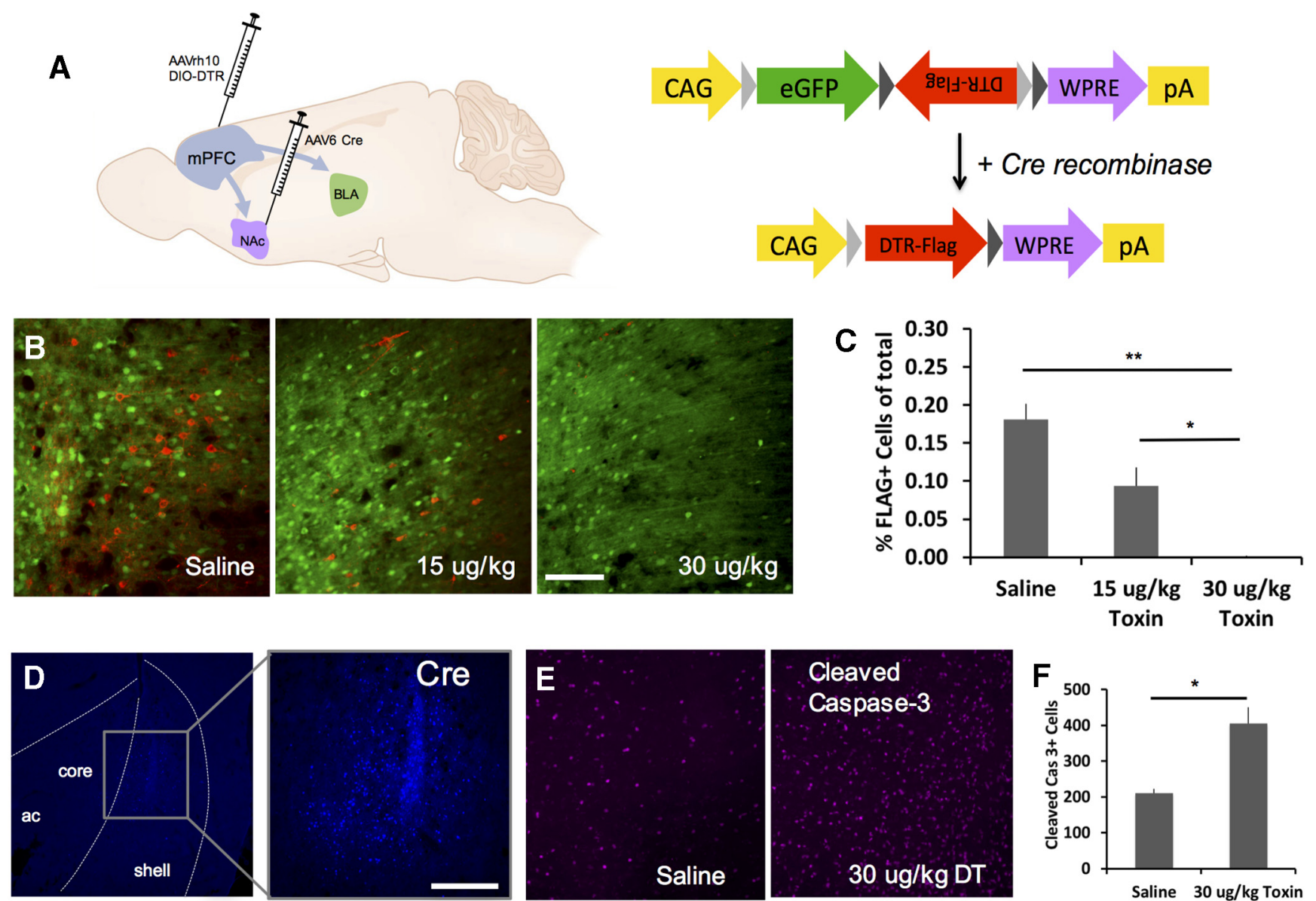

Figure 1. Strategy for target-specific ablation of mPFC afferents. A, AAVrh10-DIO-DTR-FLAG was infused into the mPFC and AAV6-Cre was infused in either the NAc (to target the mPFC $\rightarrow$ NAC pathway) or the BLA (to target the mPFC $\rightarrow$ BLA pathway). B, Representative micrographs taken after targeting the mPFC $\rightarrow$ NAc pathway. Scale bar, $100 \mu$ m. $C$, Immunohistochemical staining with a FLAG-directed antibody (red) shows a dose-dependent reduction in the percentage of total fluorescent cells that are FLAG + after intraperitoneal injection of diphtheria toxin. $(n=4$ saline, $n=4$ $15 \mu \mathrm{g} / \mathrm{kg}$, and $\left.n=430 \mu \mathrm{g} / \mathrm{kg} ;{ }^{* * *} p<0.001,{ }^{* *} p<0.01\right) \boldsymbol{D}$, Cre-directed antibody showing local expression of AAV-Cre in the NAc shell and medial core. Scale bars $300 \mu \mathrm{m}$. $\boldsymbol{E}$, $\boldsymbol{F}$, Cleaved caspase-3 staining $48 \mathrm{~h}$ after injection revealed an increased expression of this apoptosis marker in DT versus saline-treated animals. $\left(n=3\right.$ saline, $\left.n=3 \mathrm{DT} ;{ }^{*} p<0.05\right)$.

We used immunohistochemical methods to verify the placement and spread of each virus (Fig. 2D). For all experiments, animals were excluded if either virus was only visible in one hemisphere or if viral spread substantially exceeded the boundaries of the targeted structure as defined in Paxinos and Watson (2007). Fluorescence quantification revealed that DT administration was associated with a significant reduction in percentage of FLAG + cells (Fig. $\left.2 H ; t_{(11)}=8.356, p<0.001\right)$ and total FLAG + cells $\left(\right.$ saline mean $=34.5$, toxin mean $\left.=0.08 ; t_{(11)}=5.925, p<0.001\right)$ with no difference between treatment groups in GFP expression (mean GFP + cells in saline-treated animals $=196.0$, DT-treated animals $\left.=182.3 ; t_{(11)}=0.573, p=0.585\right)$. To verify that the DTR expression alone did not disrupt neural activity, we also performed a costaining for FLAG and c-Fos in 2 saline-treated animals that had been perfused $90 \mathrm{~min}$ after the reinstatement session. We observed significant overlap between FLAG and c-Fos (Fig. 2I), suggesting that DTR-expressing neurons are functional during the reinstatement session

Ablation of mPFC neurons projecting to the BLA does not affect reinstatement of alcohol seeking

A similar methodology was used to test the effects of ablating $\mathrm{mPFC}$ neurons projecting to BLA on both extinction and reinstatement of alcohol seeking. rmANOVA revealed that all animals acquired self-administration of alcohol (days 18-20 shown in Fig. 3A; effect of day: $\left.F_{(19,228)}=2.339, p=0.002\right)$, with no effect of future treatment (saline or DT, $n=7$ /group; effect of group n.s.: $F_{(1,12)}=2.634, p=0.131$; day $\times$ group interaction n.s.: $\left.F_{(19,228)}=1.011, p=0.449\right)$. After saline or DT administration, both groups of animals reduced lever pressing over the course of extinction training (Fig. $3 B$; effect of day: $F_{(4,48)}=$ $45.029, p<0.001)$, with no effect of treatment $\left(F_{(1,12)}=1.565\right.$, $p=0.235)$ or day $\times$ treatment interaction $\left(F_{(4,48)}=1.994, p=\right.$ $0.110)$. Similarly, there was no effect of treatment on the extinction of magazine entries (Fig. 3E; effect of day: $F_{(4,48)}=21.113$, $p<0.001$; effect of treatment n.s.: $F_{(1,12)}=0.180, p=0.679$; treatment $\times$ day interaction n.s.: $\left.F_{(4,48)}=1.285, p=0.289\right)$. After reaching extinction criteria, animals were subjected to a cueinduced reinstatement test as described above. Both saline- and toxin-treated animals showed reinstatement of lever pressing in response to cues (Fig. 3C; main effect of session: $F_{(1,12)}=51.071$, $p<0.001$; effect of treatment n.s.: $F_{(1,12)}=0.287, p=0.602$; session $\times$ treatment interaction n.s.: $\left.F_{(1,12)}=0.001, p=0.976\right)$. Similarly, there was no effect of treatment on reinstatement of magazine entry (Fig. 3F; main effect of session: $F_{(1,12)}=6.695$, $p=0.024$; effect of treatment n.s.: $F_{(1,12)}=0.808, p=0.386$; session $\times$ treatment n.s.: $\left.F_{(1,12)}=0.143, p=0.712\right)$. Immunohistochemical methods were used to confirm expression of DTR-FLAG and Cre (Fig. 3G,H) and to characterize the extent of viral spread (Fig. 3I). In the BLA, Cre expression was typically 

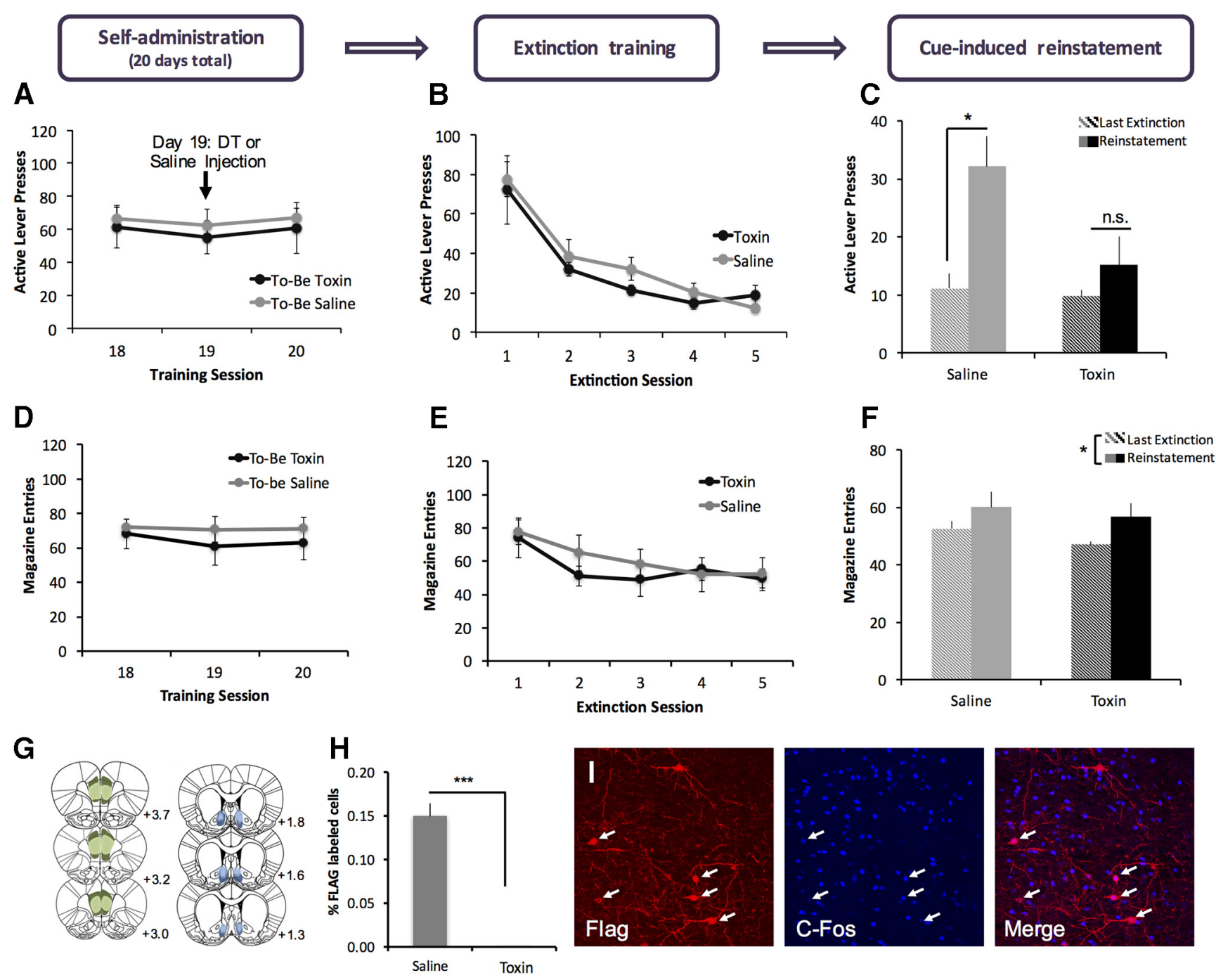

Figure 2. Ablation of NAc-projecting mPFC neurons does not affect extinction but blocks cue-induced reinstatement of lever pressing for alcohol seeking. Animals were injected with viruses to target the $\mathrm{mPFC} \rightarrow \mathrm{NAc}$ athway as described in Figure 1 and then trained to self-administer alcohol on an FR1 schedule. $A$, Final $3 \mathrm{~d}$ of self-administration showing equal levels of responding for both groups. $\boldsymbol{B}, \boldsymbol{C}$, Circuit ablation did not affect extinction training $(\boldsymbol{B})$, but blocked cue-induced reinstatement of lever pressing $(\boldsymbol{C})$ in toxin-treated animals $\left(n=6 /\right.$ group; $\left.{ }^{*} p<0.05\right)$. (All extinction and reinstatement sessions were $15 \mathrm{~min}$.) $\boldsymbol{D}-\boldsymbol{F}$, (ircuit ablation did not affect magazine entry during extinction training or the reinstatement test. $\mathbf{G}$, Schematic representation of viral spread in mPFC (DI0-DTR-FLAG) and NAc (Cre), with smallest (light colors) and largest (dark colors) acceptable spread shown. $\boldsymbol{H}$, Toxin administration dramatically reduced the percentage of FLAG-labeled cells in mPFC. $I, 10 \times$ confocal images of the mPFC of a rat killed 90 min after cue-induced reinstatement showing that Flag + neurons are also $c$-Fos + , confirming that DTR expression does not interfere with neuronal activity as measured by c-Fos activity.

strongest $\sim \mathrm{AP}-2.8$ and extended anteriorly to $\sim \mathrm{AP}-1.8$ and posteriorly to $\sim \mathrm{AP}-3.5$. DT administration reduced the percentage of FLAG expression (Fig. 3J; $t_{(13)}=7.686, p<0.001$ ) and total FLAG + cell count $\left(\right.$ saline mean $=19.7$, DT mean $=1.5 ; t_{(13)}=$ 8.363, $p<0.001$ ) significantly, with no difference in GFP expression ( saline mean $=168.1$, DT mean $\left.=142.8 ; t_{(13)}=0.188\right)$.

\section{Ablation of BLA neurons projecting to NAc affects both} extinction and reinstatement of alcohol seeking

To assess the selective contribution of BLA $\rightarrow$ NAc projections, a cohort of rats underwent ablation of this projection as described above. Injection of DIO-DTR into BLA and AAV6-Cre into NAc resulted in expression of DTR-FLAG in a subset of BLA neurons (Fig. $4 A, B$ ). Immunohistochemical methods were used to verify location and spread of viral expression (Fig. 4B). Similar to $\mathrm{mPFC} \rightarrow$ BLA animals, DIO-DTR expression was typically visible in the BLA from $\sim \mathrm{AP}-1.8$ to -3.5 , with strongest expression at AP - 2.8. Quantitative analysis of immunofluorescence in BLA revealed that DT administration reduced the percentage of FLAG expression (Fig. $4 D ; t_{(11)}=6.239, p<0.001$ ) and FLAG cell counts $\left(\right.$ saline mean $=23.5$, DT mean $=2.1 ; t_{(11)}=4.782, p=$ 0.001 ), with no difference in GFP expression (saline mean $=$ 160.0 , DT mean $\left.=185.3 ; t_{(11)}=-1.985, p=0.082\right)$.

All animals in the BLA $\rightarrow$ NAc group acquired selfadministration of alcohol as expected (Fig. $4 E, H ; F_{(19,190)}=$ 3.072, $p<0.001$ ), with no effect of future treatment (effect of drug n.s.: $F_{(1,10)}=0.229, p=0.642$; day $\times$ drug n.s.: $F_{(19,190)}=$ $0.716, p=0.799)$. As with previous groups, there was also no effect of treatment on the extinction of lever pressing (Fig. 4F; main effect of day: $F_{(4,40)}=36.903, p<0.001$; effect of drug n.s.: $F_{(1,10)}=0.249, p=0.629$; day $\times$ drug: n.s.: $F_{(4,40)}=1.171, p=$ $0.338)$. However, when we examined magazine entries across extinction training, we found an interaction between treatment and training day (Fig. $4 I$; day $\times$ drug interaction: $F_{(4,40)}=4.106$, $p=0.007$; main effect of day $F_{(4,40)}=8.953, p<0.001$; effect of treatment n.s.: $\left.F_{(1,10)}=1.905, p=0.198\right)$. Follow-up 
A
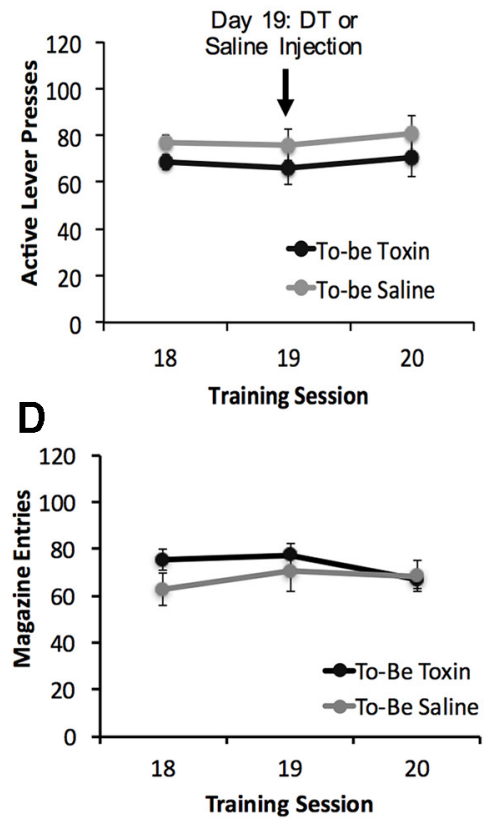

B

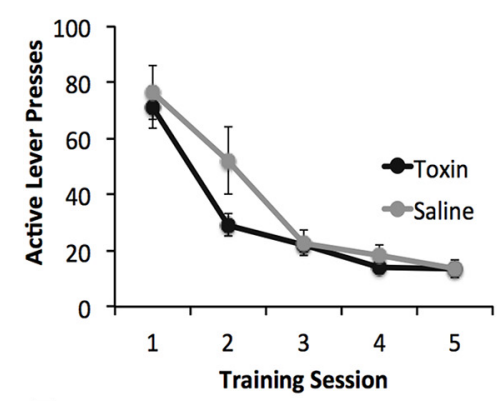

E

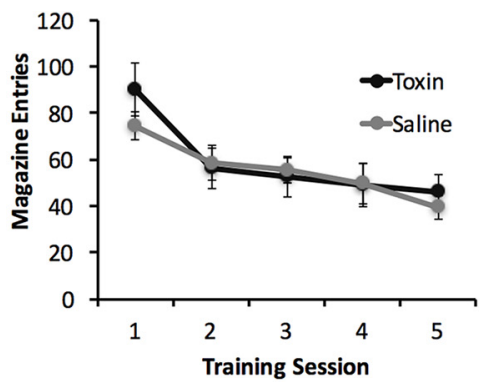

C

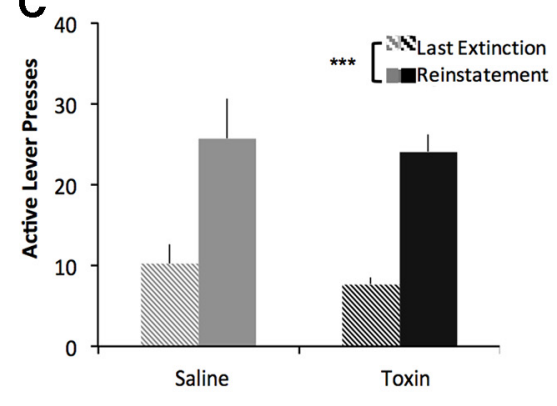

$\mathbf{F}$

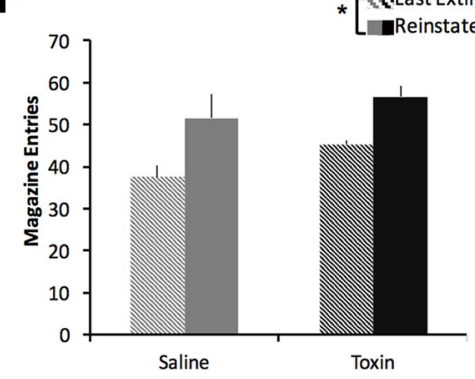

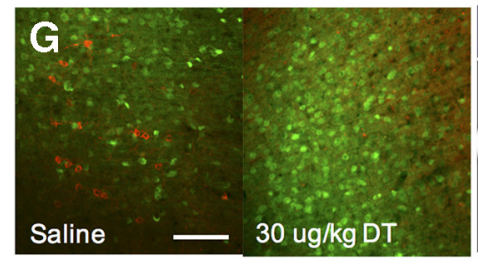
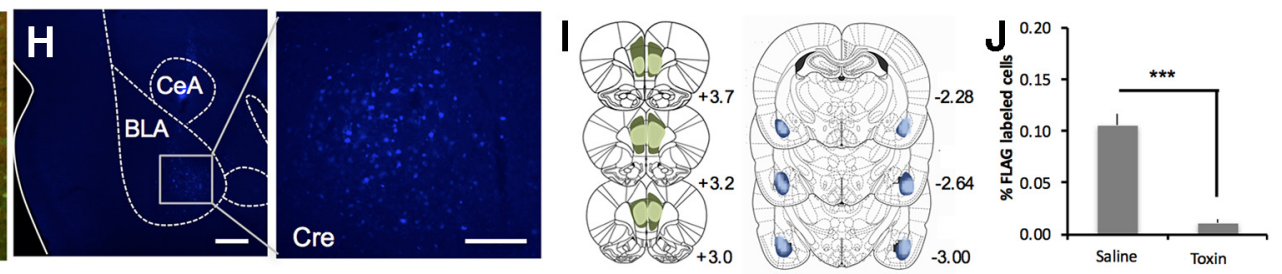

Figure 3. Ablation of BLA-projecting $\mathrm{mPFC}$ neurons does not affect extinction or reinstatement. Surgeries were performed to induce expression of DTR-FLAG in the $m P F C \rightarrow B L A$ pathway and then rats were trained on a similar set of behavior tasks. $A$, We found no difference between groups before or immediately after saline/toxin injection. $B, C, B$, Bth saline- and toxin-treated animals reduced lever pressing during extinction $(\boldsymbol{B})$ and showed a reinstatement of responding $(\boldsymbol{C})$ after exposure to alcohol-paired cues. $\boldsymbol{D}-\boldsymbol{F}$, Similarly, there was no difference between groups on extinction or reinstatement of magazine entries. G, Representative micrographs from the mPFC showing FLAG-labeled neurons (red) expressing DTR after saline treatment, but none after toxin treatment. Scale bar, $100 \mu \mathrm{m}$. H, Cre staining of local AAV6-Cre expression in BLA. Scale bars, $300 \mu \mathrm{m}$. I, Extent of viral spread in mPFC (DI0-DTR-FLAG) and BLA (Cre). J, Reduction in percentage of FLAG + cells in toxin-treated versus saline-treated animals. ( $n=7 /$ group; $\left.{ }^{*} p<0.05 ;{ }^{* * *} p<0.001\right)$.

independent-samples $t$ tests revealed no effect of drug on magazine entries during days $1-3$ of extinction training $(p>0.23$ for each day), but toxin-injected animals showed, on average, more magazine entries on day $4\left(t_{(10)}=-2.361, p=0.040\right)$ and day 5 $\left(t_{(10)}=-2.715, p=0.022\right)$. These results suggest that ablation of the amygdala-striatal pathway disrupted the ability of rodents to extinguish approach behavior to the area of alcohol delivery.

After extinction, all animals were tested on cue-induced reinstatement. Here, we found a main effect of test session (Fig. 4G; $\left.F_{(1,10)}=46.245, p<0.001\right)$, no main effect of treatment $\left(F_{(1,10)}=\right.$ $0.667, p=0.918)$, and a significant session $\times$ treatment interaction $\left(F_{(1,10)}=5.004, p=0.049\right)$. Follow-up paired-sample $t$ tests showed that both groups of animals pressed significantly more during the reinstatement session versus the last day of extinction (saline: $t_{(5)}=-6.745, p=0.001$; toxin: $t_{(5)}=-3.073, p=0.028$ ). These data suggest that, although both groups reinstated lever pressing, the degree of reinstatement was greater in saline- versus toxin-treated animals. When we examined reinstatement of magazine entries, we found that there were main effects of day (Fig. 4J; $\left.F_{(1,10)}=7.400, p=0.022\right)$ and $\operatorname{drug}\left(F_{(1,10)}=4.991, p=0.049\right)$, with no day $\times$ treatment interaction $\left(F_{(1,10)}=0.276, p=0.611\right)$. Together, these data suggest that ablation of the BLA $\rightarrow$ NAc pathway resulted in elevated magazine entries overall, but both groups showed an increase in magazine entries in response to the alcohol-paired cues.

\section{Discussion}

Here, we investigated how precise cortico-limbic-striatal projections regulate extinction and reinstatement of alcohol seeking. To accomplish this, we implemented a combinatorial viral approach to express DTRs in specific projections among $\mathrm{mPFC}, \mathrm{NAc}$, and BLA. This strategy rendered the targeted pathway subject to ablation by systemic injection of DT while sparing other corticolimbic-striatal projections. After viral infusions, we trained rats to self-administer alcohol and then tested the effect of ablating each projection on our behavioral model of alcohol seeking. We found that ablating mPFC projections to NAc, but not to BLA, blocks cue-induced reinstatement of lever pressing for alcohol. Ablating the BLA to NAc pathway disrupts extinction of approach for alcohol, as measured by magazine entries, and attenuates reinstatement of lever pressing. Together, these data provide insight into the neural control of alcohol seeking and suggest that the NAc acts as an integrator of motivational signals from the mPFC and BLA.

\section{Combinatorial viral approach allowed specific ablation of} neuronal populations based on their projection site

To achieve ablation of specific pathways, we developed a viral approach combining an AAVrh10 construct encoding Cre-dependent expression of DTR-FLAG with a retrogradely transported AAV6Cre construct. Because DTR expression is Cre dependent, it is re- 
A

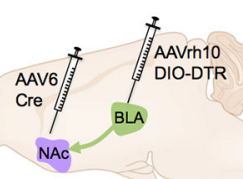

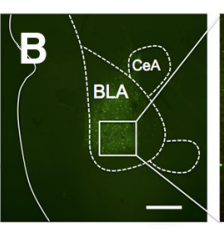

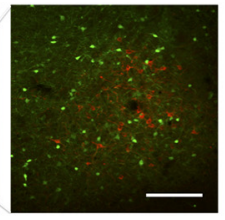

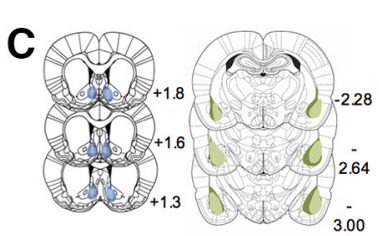
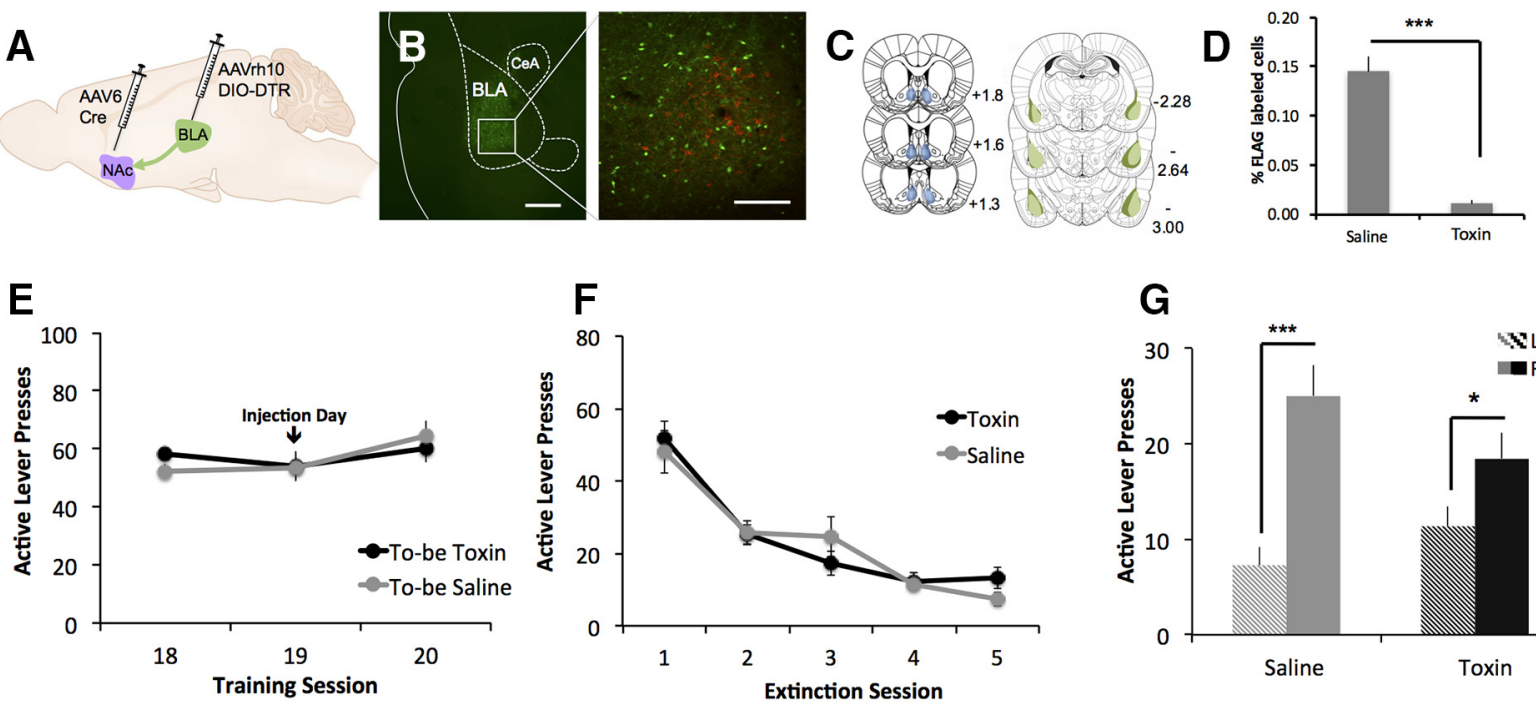

\section{G}
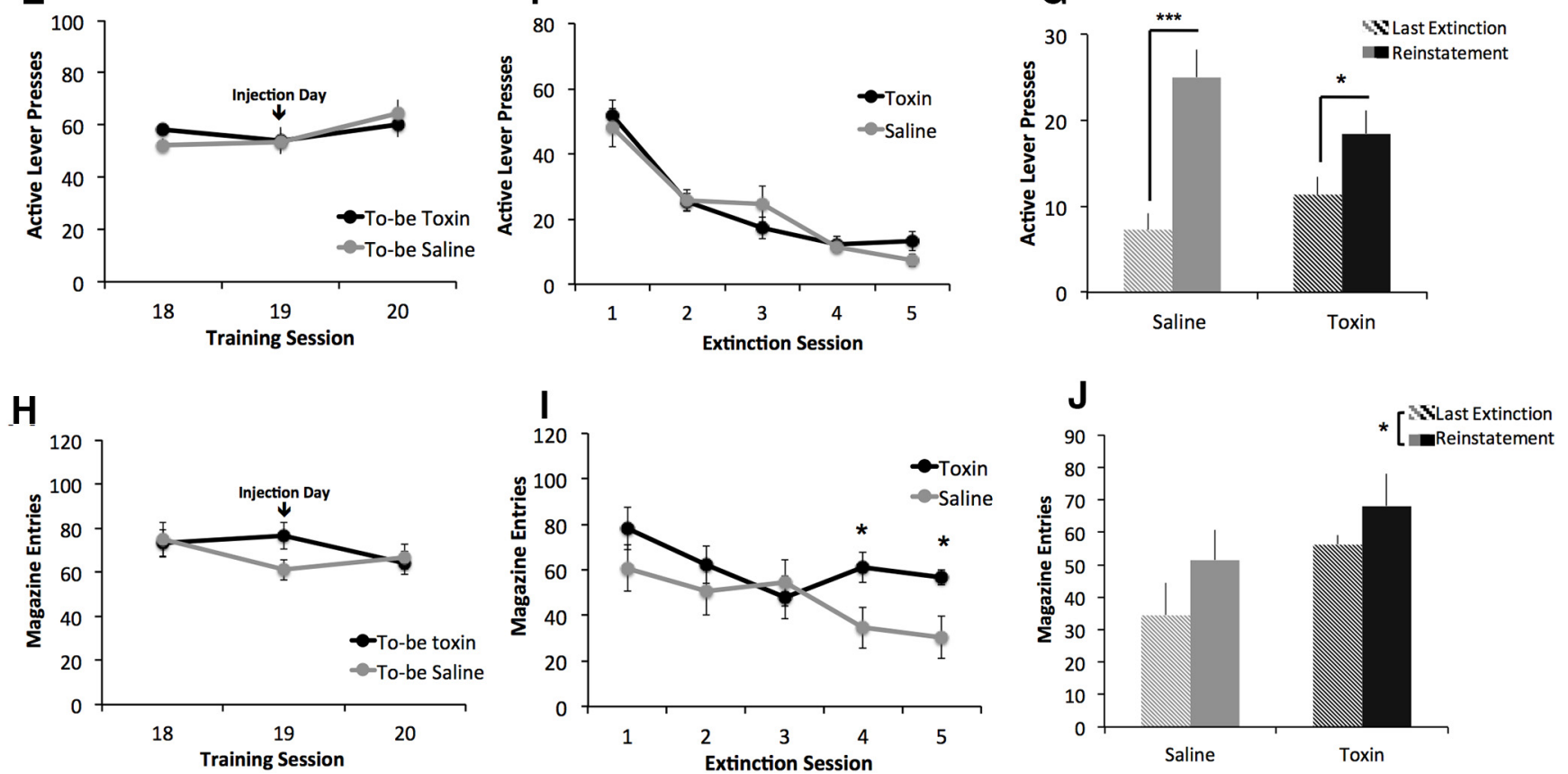

Figure 4. Ablation of NAc-projecting BLA neurons disrupts extinction of alcohol seeking. A, AAVrh10-DI0-DTR was injected in BLA and AAV6-Cre was injected into NAc. B, FLAG-positive neurons (red) in the BLA expressing DTRs and projecting to the NAc. C, Extent of viral expression. D, DT administration decreases percentage of FLAG + expression. Animals receiving saline or toxin showed no difference in lever pressing $(\boldsymbol{E})$ or magazine entry $(\boldsymbol{H})$ on the last $3 \mathrm{~d}$ of self-administration. During extinction training, both groups showed similar extinction of lever pressing $(\boldsymbol{F})$, but toxin-treated animals showed a resistance to extinction of magazine entries $(\boldsymbol{I})$. Both groups of animals reinstated lever pressing $(\boldsymbol{G})$ and magazine entry $(\boldsymbol{J})$ in response to presentation of the alcohol-paired cues. ( $n=6 /$ group; $\left.{ }^{*} p<0.05 ;{ }^{* *} p<0.001\right)$.

stricted to cells projecting from the site of the AAVrh10-DIO-DTRFLAG infection to the site of AAV6-Cre infection. Therefore, injection of the DTR-expressing virus into mPFC and AAV6-Cre into NAc induced expression of DTR-FLAG only in mPFC neurons that project to NAc. Immunohistochemical staining allowed us to label the targeted circuits and confirm that intraperitoneal DT injection resulted in dose-dependent ablation (Fig. $1 B, C$ ). Staining with a cleaved caspase- 3 antibody further confirmed that DT injection induced apoptosis at $48 \mathrm{~h}$ after injection (Fig. $1 E, F$ ). Previous studies have used selective expression of DTR as a method for killing populations of neurons defined by their neurochemical phenotype or spatial location (Gropp et al., 2005; Carter et al., 2013; Xu et al., 2015). Our methodology expands on previous techniques to ablate neurons in a structure that project to a distinct target site, thereby killing these neurons in a directionally specific manner. Importantly, the combinatorial approach also allows for temporal control because DT can be injected at any behavioral time point. Because rats are not sensitive to DT (Coca et al., 1921; Middlebrook and Dorland, 1977; Naglich and Eidels, 1990), we did not include a group to test the behavioral effects of DT injection absent expression of DTRs. However, previous work demonstrates that DT administration in normal rodents, even at higher doses than the one used in this study, does not affect health or behavior (Gropp et al., 2005; Han et al., 2009). In addition, the null effect of DT injection in the $\mathrm{mPFC} \rightarrow$ BLA group demonstrates indirectly that toxin alone does not affect behavior.
Other studies have accomplished directionally specific chemogenetic inhibition using floxed DREADDs instead of floxed DTR (Carter et al., 2013; Kerstetter et al., 2016). Although a DREADD-based method allows for reversible neuronal inhibition, titrating $\mathrm{CNO}$ dosage can be difficult and repeated intraperitoneal injections of $\mathrm{CNO}$ can introduce stress that might interfere with behavior. Nonetheless, excitatory DREADDs could be used to examine activation of cortico-limbic-striatal circuits in alcohol seeking.

\section{$\mathrm{mPFC} \rightarrow$ NAc pathway is necessary for cue-triggered} reinstatement of alcohol seeking

Although ablation of the mPFC $\rightarrow$ NAc pathway did not affect extinction (Fig. 2B), there was a loss of cue-induced reinstatement in toxin-injected animals (Fig. 2C). Further, we saw that neurons expressing DTR were active during cue-induced reinstatement (Fig. 2E), confirming that the expression of these receptors did not interfere with neuronal activity. This is a novel and robust demonstration that mPFC projections to NAc are necessary for cue-induced reinstatement of alcohol seeking. Our data are consistent with experiments showing the following: (1) mPFC and NAc are activated by exposure to alcohol-paired cues after extinction (Dayas et al., 2007); (2) inactivating NAc attenuates cued alcohol seeking (Chaudhri et al., 2010; Millan et al., 2015); and (3) inactivating mPFC does not disrupt expression 


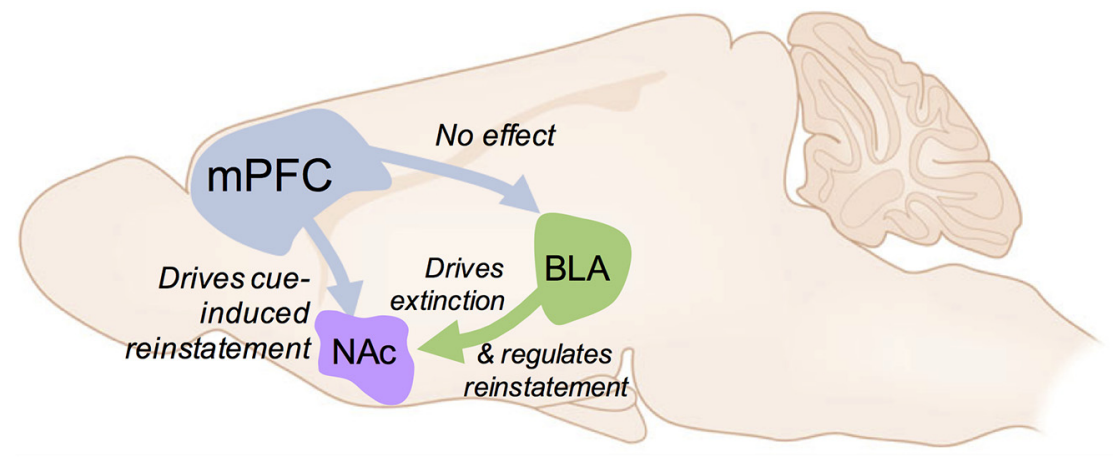

Figure 5. Hypothesized role of circuitry mediating extinction and reinstatement of alcohol seeking. Our data suggest that projections from the mPFC to the NAc, but not to the BLA, are necessary for cue-induced reinstatement of alcohol seeking. Neurons projecting from the BLA to the NAc regulate both extinction and reinstatement of these behaviors.

of extinction (Willcocks and McNally, 2013). They are also consistent with work showing that inhibition of $\mathrm{mPFC} \rightarrow \mathrm{NAc}$, and the prelimbic to core subcircuit in particular, attenuates reinstatement of cocaine seeking after extinction (Kerstetter et al., 2016; Stefanik et al., 2016).

\section{$\mathrm{mPFC} \rightarrow$ BLA pathway is not necessary for extinction or reinstatement of alcohol seeking}

In a separate set of experiments, we tested the effects of ablating $\mathrm{mPFC}$ neurons projecting to BLA. Here, we found no effect of ablation on either extinction or reinstatement (Fig. 2E,F), suggesting that $\mathrm{mPFC}$ afferents to BLA are not required for these behaviors. Combined with our initial experiments, these data suggest a dissociation of $\mathrm{mPFC}$ function in this context. Specifically, mPFC neurons that project to the NAc are necessary for cue-induced reinstatement of alcohol seeking, whereas those that project to the BLA are not. Other experiments have shown that the BLA is an important regulator of alcohol seeking in response to conditioned cues and contexts (Chaudhri et al., 2013; Sciascia et al., 2015). However, whereas the function of mPFC neurons that project to the BLA has been examined in the context of food seeking (Petrovich et al., 2005; Land et al., 2014), a role of this pathway in alcohol seeking has not been investigated directly. There is evidence that the mPFC-central amygdala pathway is important for regulating alcohol intake (George et al., 2012) and our data may indicate that projections to the BLA are functionally distinct in this regard. In addition, there is an emerging literature demonstrating that neuronal ensembles in MPFC and amygdala regulate alcohol seeking and taking (Pfarr et al., 2015; de Guglielmo et al., 2016). Our data complement this approach and could suggest that the effects of these ensembles are mediated by their downstream targets.

\section{$\mathrm{BLA} \rightarrow \mathrm{NAc}$ pathway regulates extinction of approach and reinstatement of lever pressing}

In addition to their interactions with the $\mathrm{MPFC}, \mathrm{BLA}$ and NAc are also connected by a strong glutamatergic projection. This projection has been studied extensively in the context of motivated behaviors and is believed to be important for responding to reward-predictive cues (Cador et al., 1989; Stuber et al., 2011; Stefanik and Kalivas, 2013; Wassum and Izquierdo, 2015). In the domain of alcohol, there is evidence suggesting that the $\mathrm{BLA} \rightarrow \mathrm{NAc}$ pathway plays a role in both inhibition and seeking (Millan and McNally, 2011; Sinclair et al., 2012; Millan et al., 2015). Indeed, our data show that ablation of this projection affects both extinction and reinstatement. In particular, we found that $\mathrm{BLA} \rightarrow \mathrm{NAc}$ ablation results in a resistance to extinction of approach for alcohol as measured by head entries in the magazine port (Fig. $4 F$ ). This effect did not appear until day 4 , which may suggest that ablation interferes with late-stage but not early-stage extinction. Interestingly, there was no effect on extinction of lever pressing (Fig. 4E), indicating that projections from BLA to NAc regulate extinction of approach but not instrumental responding. Further, our data show that ablating $\mathrm{BLA} \rightarrow \mathrm{NAc}$ attenuated reinstatement of lever pressing, although it did not affect reinstatement of magazine entries. This is consistent with previous findings that the circuit regulates cue-triggered appetitive responding for sucrose (Stuber et al., 2011) and cocaine (Stefanik and Kalivas, 2013) and that glutamate levels in these structures are elevated in alcohol seeking (Gass et al., 2011).

\section{Additional comments and conclusion}

Although our data demonstrate that $\mathrm{MPFC}$ and BLA input to NAc regulate alcohol-seeking behaviors, an important constraint is that we did not dissociate between subregions of the NAc (i.e., the shell and core). In the context of cocaine intake and other motivated behaviors, there is strong evidence showing that infralimbic projections to the shell regulate extinction and prelimbic projections to core regulate reinstatement (Peters et al., 2009; Gourley and Taylor, 2016). Although these circuits have not been explored as fully in alcohol-seeking paradigms, recent studies demonstrate that the infralimbic cortex may serve a similar, inhibitory role that facilitates extinction of alcohol seeking (Barker et al., 2012; Pfarr et al., 2015), perhaps through projections to the shell (Meinhardt et al., 2013). Similarly, there is evidence that BLA projections to the core versus the shell may regulate reward seeking differentially (Millan and McNally, 2011; Stefanik and Kalivas, 2013). Future experiments could be conducted to ablate these subcircuits separately and test the effect on extinction and cued reinstatement. In addition, cell-type-specific circuit-level mechanisms of $\mathrm{mPFC} \rightarrow \mathrm{NAc}$ regulation of cue-induced reinstatement are warranted after reports suggesting the involvement of $\mu$-opioid and D1 dopamine receptors in the reinstatement of alcohol seeking behaviors (Chaudhri et al., 2009; Perry and McNally, 2013). Furthermore, we targeted the anterior BLA and did not include subjects with significant viral expression beyond AP coordinate -4.0 . Given evidence for a functional distinction of anterior and posterior BLA in cue-motivated behavior for both alcohol (Millan et al., 2015) and cocaine (Kantak et al., 2002), future experiments could investigate the effects of disconnecting $\mathrm{mPFC}$ and striatum from more posterior regions of basal amygdala.

In summary, we have demonstrated the feasibility of ablating specific populations of neurons based on their projection targets. Using this strategy, we demonstrate that different inputs to the NAc serve distinct roles in alcohol-seeking behavior: mPFC neurons projecting to NAc but not BLA are necessary for cue-induced reinstatement and BLA neurons projecting to NAc are necessary for both extinction of approach and for regulating reinstatement (Fig. 5). These data provide potential insight into findings from the clinical literature showing increased mesocorticolimbic activation to alcohol-paired cues in alcohol-dependent individuals (Heinz et al., 2009; Bühler and Mann, 2011). They are also consistent with the finding 
that striatal glutamate levels are upregulated in recently detoxified patients (Bauer et al., 2013) and could suggest that glutamatergic projections from mPFC supply this tone. Further, our finding that $\mathrm{BLA} \rightarrow \mathrm{NAc}$ regulates extinction could suggest that signals from $\mathrm{mPFC}$ and BLA are integrated in NAc to guide seeking behavior. In conclusion, these results further our understanding of the precise neural control of alcohol seeking and could help to inform the future development of more targeted pharmacotherapeutics for these disorders.

\section{References}

Abernathy K, Chandler LJ, Woodward JJ (2010) Alcohol and the prefrontal cortex. Int Rev Neurobiol 91:289-320. CrossRef Medline

Barker JM, Torregrossa MM, Taylor JR (2012) Low prefrontal PSA-NCAM confers risk for alcoholism-related behavior. Nat Neurosci 15:1356-1358. CrossRef Medline

Bauer J, Pedersen A, Scherbaum N, Bening J, Patschke J, Kugel H, Heindel W, Arolt V, Ohrmann P (2013) Craving in alcohol-dependent patients after detoxification is related to glutamatergic dysfunction in the nucleus accumbens and the anterior cingulate cortex. Neuropsychopharmacology 38:1401-1408. CrossRef Medline

Bossert JM, Marchant NJ, Calu DJ, Shaham Y (2013) The reinstatement model of drug relapse: recent neurobiological findings, emerging research topics, and translational research. Psychopharmacology 229:453-476. CrossRef Medline

Bühler M, Mann K (2011) Alcohol and the human brain: a systematic review of different neuroimaging methods. Alcohol Clin Exp Res 35:17711793. CrossRef Medline

Cador M, Robbins TW, Everitt BJ (1989) Involvement of the amygdala in stimulus-reward associations: interactions with the ventral striatum. Neuroscience 30:77-86. Medline

Carter ME, Soden ME, Zweifel LS, Palmiter RD (2013) Genetic identification of a neural circuit that suppresses appetite. Nature 503:111-114. CrossRef Medline

Chaudhri N, Sahuque LL, Janak PH (2009) Ethanol seeking triggered by environmental context is attenuated by blocking dopamine D1 receptors in the nucleus accumbens core and shell in rats. Psychopharmacology 207:303-314. CrossRef Medline

Chaudhri N, Sahuque LL, Schairer WW, Janak PH (2010) Separable roles of the nucleus accumbens core and shell in context- and cueinduced alcohol-seeking. Neuropsychopharmacology 35:783-791. CrossRef Medline

Chaudhri N, Woods CA, Sahuque LL, Gill TM, Janak PH (2013) Unilateral inactivation of the basolateral amygdala attenuates context-induced renewal of Pavlovian-conditioned alcohol-seeking. Eur J Neurosci 38: 2751-2761. CrossRef Medline

Ciccocioppo R, Angeletti S, Weiss F (2001) Long-lasting resistance to extinction of response reinstatement induced by ethanol-related stimuli: role of genetic ethanol preference. Alcohol Clin Exp Res 25:1414-1419. CrossRef Medline

Coca AF, Russell EF, Baughman WH (1921) The reaction of the rat to diphtheria toxin. J Immunol 6:387-398.

Dayas CV, Liu X, Simms JA, Weiss F (2007) Distinct patterns of neural activation associated with ethanol seeking: effects of naltrexone. Biological Psychiatry 61:979-989. CrossRef Medline

de Guglielmo G, Crawford E, Kim S, Vendruscolo LF, Hope BT, Brennan M, Cole M, Koob GF, George O (2016) Recruitment of a neuronal ensemble in the central nucleus of the amygdala is required for alcohol dependence. J Neurosci 36:9446-9453. CrossRef Medline

Field M, Duka T (2002) Cues paired with a low dose of alcohol acquire conditioned incentive properties in social drinkers. Psychopharmacology 159:325-334. CrossRef Medline

Gass JT, Sinclair CM, Cleva RM, Widholm JJ, Olive MF (2011) Alcoholseeking behavior is associated with increased glutamate transmission in basolateral amygdala and nucleus accumbens as measured by glutamateoxidase-coated biosensors. Addict Biol 16:215-228. CrossRef Medline

George O, Sanders C, Freiling J, Grigoryan E, Vu S, Allen CD, Crawford E, Mandyam CD, Koob GF (2012) Recruitment of medial prefrontal cortex neurons during alcohol withdrawal predicts cognitive impairment and excessive alcohol drinking. Proc Natl Acad Sci U S A 109:1815618161. CrossRef Medline
Gourley SL, Taylor JR (2016) Going and stopping: dichotomies in behavioral control by the prefrontal cortex. Nat Neurosci 19:656-664. CrossRef Medline

Gropp E, Shanabrough M, Borok E, Xu AW, Janoschek R, Buch T, Plum L, Balthasar N, Hampel B, Waisman A, Barsh GS, Horvath TL, Brüning JC (2005) Agouti-related peptide-expressing neurons are mandatory for feeding. Nat Neurosci 8:1289-1291. CrossRef Medline

Han JH, Kushner SA, Yiu AP, Hsiang HL, Buch T, Waisman A, Bontempi B, Neve RL, Frankland PW, Josselyn SA (2009) Selective erasure of a fear memory. Science 323:1492-1496. CrossRef Medline

Heinz A, Beck A, Grüsser SM, Grace AA, Wrase J (2009) Identifying the neural circuitry of alcohol craving and relapse vulnerability. Addict Biol 14:108-118. CrossRef Medline

Jentsch JD, Taylor JR (1999) Impulsivity resulting from frontostriatal dysfunction in drug abuse: implications for the control of behavior by reward-related stimuli. Psychopharmacology 146:373-390. CrossRef Medline

Kantak KM, Black Y, Valencia E, Green-Jordan K, Eichenbaum HB (2002) Dissociable effects of lidocaine inactivation of the rostral and caudal basolateral amygdala on the maintenance and reinstatement of cocaineseeking behavior in rats. J Neurosci 22:1126-1136. Medline

Kerstetter KA, Wunsch AM, Nakata KG, Donckels E, Neumaier JF, Ferguson SM (2016) Corticostriatal afferents modulate responsiveness to psychostimulant drugs and drug-associated stimuli. Neuropsychopharmacology 41:1128-1137. CrossRef Medline

Koob GF, Volkow ND (2010) Neurocircuitry of addiction. Neuropsychopharmacology 35:217-238. CrossRef Medline

Land BB, Narayanan NS, Liu RJ, Gianessi CA, Brayton CE, Grimaldi DM, Sarhan M, Guarnieri DJ, Deisseroth K, Aghajanian GK, DiLeone RJ (2014) Medial prefrontal D1 dopamine neurons control food intake. Nat Neurosci 17:248-253. CrossRef Medline

Lê AD, Shaham Y (2002) Neurobiology of relapse to alcohol in rats. Pharmacol Ther 94:137-156. CrossRef Medline

Meinhardt MW, Hansson AC, Perreau-Lenz S, Bauder-Wenz C, Stählin O, Heilig M, Harper C, Drescher KU, Spanagel R, Sommer WH (2013) Rescue of infralimbic mGluR2 deficit restores control over drug-seeking behavior in alcohol dependence. J Neurosci 33:2794-2806. CrossRef Medline

Middlebrook JL, Dorland RB (1977) Response of cultured mammalian cells to the exotoxins of Pseudomonas aeruginosa and Corynebacterium diphtheriae: differential cytotoxicity. Can J Microbiol 23:183-189. CrossRef Medline

Millan EZ, McNally GP (2011) Accumbens shell AMPA receptors mediate expression of extinguished reward seeking through interactions with basolateral amygdala. Learn Mem 18:414-421. CrossRef Medline

Millan EZ, Reese RM, Grossman CD, Chaudhri N, Janak PH (2015) Nucleus accumbens and posterior amygdala mediate cue-triggered alcohol seeking and suppress behavior during the omission of alcohol-predictive cues. Neuropsychopharmacology 40:2555-2565. CrossRef Medline

Naglich JG, Eidels L (1990) Isolation of diphtheria toxin-sensitive mouse cells from a toxin-resistant population transfected with monkey DNA. Proc Natl Acad Sci U S A 87:7250-7254. Medline

Paxinos G, Watson C (2007) The rat brain in stereotaxic coordinates, 6th edn. Burlington: Elsevier Academic Press.

Perry CJ, McNally GP (2013) $\mu$-Opioid receptors in the nucleus accumbens shell mediate context-induced reinstatement (renewal) but not primed reinstatement of extinguished alcohol seeking. Behav Neurosci 127:535543. CrossRef Medline

Peters J, Kalivas PW, Quirk GJ (2009) Extinction circuits for fear and addiction overlap in prefrontal cortex. Learn Mem 16:279-288. CrossRef Medline

Petrovich GD, Holland PC, Gallagher M (2005) Amygdalar and prefrontal pathways to the lateral hypothalamus are activated by a learned cue that stimulates eating. J Neurosci 25:8295-8302. CrossRef Medline

Pfarr S, Meinhardt MW, Klee ML, Hansson AC, Vengeliene V, Schönig K, Bartsch D, Hope BT, Spanagel R, Sommer WH (2015) Losing control: excessive alcohol seeking after selective inactivation of cue-responsive neurons in the infralimbic cortex. J Neurosci 35:10750-10761. CrossRef Medline

Substance Abuse and Mental Health Services Administration (2014) Results from the 2013 National Survey on Drug Use and Health: summary of national findings. Available from: https://www.samhsa.gov/data/sites/default/ 
files/NSDUHresultsPDFWHTML2013/Web/NSDUHresults2013.pdf. Accessed: September 1, 2016.

Sciascia JM, Reese RM, Janak PH, Chaudhri N (2015) Alcohol-seeking triggered by discrete Pavlovian cues is invigorated by alcohol contexts and mediated by glutamate signaling in the basolateral amygdala. Neuropsychopharmacology 40:2801-2812. CrossRef Medline

Sinclair CM, Cleva RM, Hood LE, Olive MF, Gass JT (2012) mGluR5 receptors in the basolateral amygdala and nucleus accumbens regulate cueinduced reinstatement of ethanol-seeking behavior. Pharmacol Biochem Behav 101:329-335. CrossRef Medline

Sinha R, Li CS (2007) Imaging stress- and cue-induced drug and alcohol craving: association with relapse and clinical implications. Drug Alcohol Rev 26:25-31. CrossRef Medline

Stefanik MT, Kalivas PW (2013) Optogenetic dissection of basolateral amygdala projections during cue-induced reinstatement of cocaine seeking. Front Behav Neurosci 7:213. CrossRef Medline

Stefanik MT, Kupchik YM, Kalivas PW (2016) Optogenetic inhibition of cortical afferents in the nucleus accumbens simultaneously prevents cueinduced transient synaptic potentiation and cocaine-seeking behavior. Brain Struct Funct 221:1681-1689. CrossRef Medline

Stuber GD, Sparta DR, Stamatakis AM, van Leeuwen WA, Hardjoprajitno JE,
Cho S, Tye KM, Kempadoo KA, Zhang F, Deisseroth K, Bonci A (2011) Excitatory transmission from the amygdala to nucleus accumbens facilitates reward seeking. Nature 475:377-380. CrossRef Medline

Wassum KM, Izquierdo A (2015) The basolateral amygdala in reward learning and addiction. Neurosci Biobehav Rev 57:271-283. CrossRef Medline

Weiss F (2005) Neurobiology of craving, conditioned reward and relapse. Curr Opin Pharmacol 5:9-19. CrossRef Medline

Willcocks AL, McNally GP (2013) The role of medial prefrontal cortex in extinction and reinstatement of alcohol-seeking in rats. Eur J Neurosci 37:259-268. CrossRef Medline

Xu M, Kobets A, Du JC, Lennington J, Li L, Banasr M, Duman RS, Vaccarino FM, DiLeone RJ, Pittenger C (2015) Targeted ablation of cholinergic interneurons in the dorsolateral striatum produces behavioral manifestations of Tourette syndrome. Proc Natl Acad Sci U S A 112:893-898. CrossRef Medline

Xu M, Li L, Pittenger C (2016) Ablation of fast-spiking interneurons in the dorsal striatum, recapitulating abnormalities seen postmortem in Tourette syndrome, produces anxiety and elevated grooming. Neuroscience 324:321329. CrossRef Medline 